\title{
Economics of a variable rate fertiliser strategy on a Whanganui hill country station
}

M.D. WHITE ${ }^{1}$, A.K. METHERELL ${ }^{2}$, A.H.C. ROBERTS 3 , R.E. MEYER ${ }^{4}$ and T.A. CUSHNAHAN ${ }^{5}$ Ravensdown Ltd., Private Bag 6012, Awatoto, Napier 4110, New Zealand

${ }^{2}$ Ravensdown Ltd, PO Box 1049, Christchurch 8140, New Zealand ${ }^{3}$ Ravensdown Ltd., PO Box 608, Pukekohe 2340, New Zealand ${ }^{4}$ Ravensdown Ltd., Corner State Highway 1 and Putorino Road, Rata, 4787, New Zealand ${ }^{5}$ Centre for Precision Agriculture, Massey University, Palmerston North 4442, New Zealand michael.white@ravensdown.co.nz

\section{Abstract}

Automated flow control coupled to differential GPS guidance systems in aerial topdressing aircraft will allow variable rate (VR) fertiliser strategies to be applied on hill country farms. The effectiveness of these strategies will be enhanced with the use of remotely sensed hyperspectral data to categorise and quantify the farm landscape in greater detail. The economic benefit of a variable rate fertiliser strategy in comparison to a single rate (blanket) strategy was evaluated for a case study Whanganui hill country station. The analysis illustrates the robustness of a VR strategy in the face of volatile returns in that it produced a higher 10 year cumulative net present value (NPV) and remained at a positive advantage at three different stock gross margins, in comparison to a blanket approach. The effectiveness of hyperspectral imagery for defining effective pasture areas to assist development of more precise variable rate fertiliser applications, compared to the current visual classification from farm photography is discussed.

Keywords: economic benefit, variable rate fertiliser, hyperspectral data

\section{Introduction}

There is a wealth of scientific evidence showing that the addition of the fertiliser nutrients phosphorus $(\mathrm{P})$, potassium $(\mathrm{K})$, sulphur $(\mathrm{S})$ and lime increase pasture production and quality in New Zealand hill country (Roberts \& White 2016; Morton \& Roberts 2009). However, hill country farms also have a myriad of slopes, aspects, soil types, soil depths, moisture status, grazing management and pasture composition status, gazing me sosition in in pasture prodution, which then impact animal performance and farm profitability. Historically, available technology and practicalities have resulted in aerial fertiliser applications to hill country usually being a single rate of a single product (Roberts \& White 2016; Morton et al. 2016) sometimes referred to as a blanket (B) application.

The benefit of a variable rate fertiliser application as opposed to blanket application has previously been advanced as an improved strategy for hill country farms Yule \& Gillingham 2002; Murray \& Yule 2007; White et al. 2017).

Applying a variable rate (VR) strategy has been referred to in two commercial examples in Edmeades et al. (2016) and broadly includes:

- Classifying the farm into different land management units (LMU) based on an assessment of actual and potential productivity of these units

- Undertaking soil and herbage sampling to assess the soil fertility of these units

- Using an econometric modelling approach (Metherell et al. 1996) to allocate fertiliser and lime applications (including capital and maintenance) across the LMUs to achieve the optimum outcome either by increasing productivity by applying more nutrients or increasing productivity by applying more nutrients or by achieving cost reductio
application is justified.

The recent advent of automated flow control of aeria topdressing application systems has facilitated the preading of the nominated fertiliser rate to the intended area of application. One of the critical components for using this new technology is that it requires a current digital image of the farm to effectively map the ensitive and/or non-productive areas. These systems have also been shown to reduce the field coefficient of variation $(\mathrm{CV})$ of aerial fertiliser application from $78 \%$ to $42 \%$, which is aligned with CV values foun in ground spreading (Chok et al. 2016). Morton et al. (2016) concluded benefits from variable rate equipped aircraft can be both economic and environmenta due to the avoidance of non-productive zones and/or do the avidy se of non-productive zons andor -automated systems for fertiliser application an also avoid non-productive zones and change fertiliser rates manually while in the air. However, in practice this represents an enormous strain on the pilot and the effectiveness may vary. Automation will also mprove pilot safety as they are able to focus on aircraft operation rather than fertiliser spreading.

Remotely sensed hyperspectral imagery can 
differentiate pasture species from other plant species in the landscape to an accuracy of $99 \%$ (Cushnahan et al. 2017). This should allow for more accurate assessment of productive pasture area. Hyperspectral imagery wa also shown to have potential to accurately classify landscape components such as pine trees, manuka, gum trees, rushes, farm tracks, open soil and wate bodies (Cushnahan et al. 2017). This offers potential fo such imagery to inform fertiliser prescription maps for variable rate application by automating the process of defining non-pasture areas and environmentally sensitive areas where fertiliser application is not required.

The objective of this paper was to compare a case study of the economics of a variable rate fertilise strategy with a blanket strategy for a Whanganui hill country farm (Ohorea Station). Additionally, the effectiveness of hyperspectral imagery for defining pasture areas to develop variable rate fertilise applications is discussed.

\section{Methods and analysis}

conomic analysis of variable rate

The economics of a variable rate fertiliser strategy as compared to a blanket strategy was evaluated for Ohorea Station, a 5420 ha breeding and finishing hill country farm located in the Parapara range (ManawatuWhanganui). Overseer ${ }^{\mathbb{B}}$ (version 6.23) was used to

model Ohorea Station's current farm management. The form production and physical characteristics are described in Table 1. The soil classification and fertility characteristics are shown in Table 2. The mean soil fertility levels for each LMU were determined from permanent representative soil transects already established in each LMU as part of the annual farm planning cycle. The current analysis considered $\mathrm{P}, \mathrm{K}$ and $\mathrm{S}$ requirements only. The AgResearch PKS lime econometric model (Metherl et al 1996) was used to deterine optim (Meil fetility levels, assocised r per and comparison of practical fertiliser strategies. The key model inputs are shown in Table 3. A blanket strategy, based on recent farm practise, was modelled as $200 \mathrm{~kg}$ / ha of single superphosphate (SSP) applied annually (except for an unfertilised area of steep hill country). A variable rate scenario, using available fertiliser products, was created to approximate the nutrient rates and ratios recommended by the optimum analysis. A sensivity analysis to test the robustness of the strategy to changes of $\pm 20 \%$ in livestock gross margin was also completed.

\section{Using hyperspectral imagery to measure effective} area in pasture

Ohorea Station is being used as a research/focus farm, involved in a Primary Growth Partnership programme to assist calibration of a hyperspectral sensor, with the

Table 1 Ohorea Station production and physical characteristics for econometric analysis.

\begin{tabular}{lccccc}
\hline LMUs & $\begin{array}{c}\text { Block area } \\
\text { (ha) }\end{array}$ & $\begin{array}{c}\text { Slope } \\
\text { (degrees) }\end{array}$ & Soil Order & $\begin{array}{c}\text { Sheep } \\
\text { (RSU/ha) }\end{array}$ & $\begin{array}{c}\text { Beef } \\
\text { (RSU/ha) }\end{array}$ \\
\hline Class 1 & 65 & Flat $\left(0^{\circ}-7^{\circ}\right)$ & Allophanic & 659 & 311 \\
Class 2 - GFC & 299 & Rolling $\left(8^{\circ}-15^{\circ}\right)$ & Allophanic & 3035 & 1434 \\
Class 2 - no crops & 905 & Rolling $\left(8^{\circ}-15^{\circ}\right)$ & Allophanic & 7336 & 3484 \\
Class 3 - Fertilised & 2582 & Steep $\left(>26^{\circ}\right)$ & Brown & 15720 & 7437 \\
Class 3 - Unfertilised & 288 & Steep $\left(>26^{\circ}\right)$ & Brown & 833 & 397 \\
\hline
\end{tabular}

greenfeed crop

Table 3 Key inputs used in the FANZ econometric model analysis.

Net Present Value (NPV) discount rate (\%)

4

Gross Margins (\$/RSU)

$$
\begin{aligned}
& \text { Sheep } \\
& \text { Beef }
\end{aligned}
$$

Table 2 Soil fertility characteristics of Ohorea Station before implementation of a VR fertiliser strategy.

\begin{tabular}{lcccc}
\hline LMUs & $\mathbf{p H}$ & $\begin{array}{c}\text { Olsen P } \\
(\boldsymbol{\mu g} / \mathbf{m l})\end{array}$ & $\begin{array}{c}\text { Quick } \\
\text { test K }\end{array}$ & $\begin{array}{c}\text { Organic S } \\
(\boldsymbol{\mu g} / \mathbf{g})\end{array}$ \\
\hline Class 1 & 6.0 & 22 & 12 & 20 \\
Class 2 - GFC & 5.8 & 32 & 17 & 22 \\
Class 2 - no crops & 5.4 & 18 & 12 & 9 \\
Class 3 - Fertilised & 5.3 & 13 & 12 & 7 \\
Class 3 - Unfertilised & 5.3 & 8 & 10 & 5 \\
\hline
\end{tabular}

\begin{tabular}{lc} 
Beef & 60.1 \\
\hline Stock value (\$/RSU) & \\
Sheep & 120 \\
Beef & 170 \\
\hline Cost of transport and spreading (\$/tonne) & \\
Class 1 & 21.38 \\
Class 2 and Class 3 & 103.6 \\
\hline Cost of nutrients (\$/kg, ex-store) & \\
P & 2.92 \\
K & 1.18 \\
S & 0.57 \\
\hline
\end{tabular}

objective of remotely sensing soil fertility across hill country farms. This is still work in progress and is not discussed in this paper. A co-benefit of the hyperspectral data is that it has enabled the percentage of pasture cover to be calculated. Approximately 927 ha of Ohorea Station has been surveyed with the hyperspectral sensor as part of the calibration exercise and also manually classified for aerial fertiliser application using standard aerial imagery. Using the hyperspectral using sta cur on part of Ohore Sation ino pastre and a variety of non-pasture classes a a resoluin $11 \mathrm{~m}^{2}$ pixels. create an efecive at a resoltion of 1 ma pixels. To ere application, this vegetation layer was processed by calculating the proportion of $1 \mathrm{~m}^{2}$ pasture pixels in 100 $\mathrm{m}^{2}$ grid cells. Where there was greater than $50 \%$ pasture the grid cell was classified as pasture. This was then simplified by eliminating small areas of either pasture or non-pasture less the $0.5 \mathrm{ha}$ and than about $70 \mathrm{~m}$ in width. This calculated area could then be compared to the pasture area determined by visual classification and the total pasture area from the original $1 \mathrm{~m}^{2}$ resolution hyperspectral classification. The visual classification involved manually editing the farm map using GIS software.

\section{Results}

\section{Economic analysis of variable rate strategy}

The VR strategy applied a different rate of SSP each year for Class 1, Class 2 - no crops, Class 3 - fertilise LMU's of 180,170 and $200 \mathrm{~kg} \mathrm{SSP} / \mathrm{ha}$, respectively (Table 4). For the Class 2 - GFC LMU, P was withheld for 7 years and when resumed in year eight, was applied at a rate of $200 \mathrm{~kg} \mathrm{SSP} / \mathrm{ha}$ (Table 4). For the Class 3 Unfertilised LMU Maxi SSP at $100 \mathrm{~kg} / \mathrm{ha}$ was applied in Year 1 and from Year 2 onwards was changed to sulphur fortified SSP (SS20) (Table 4).

A maintenance P strategy maintains soil Olsen P levels while a capital P strategy aims to increase these levels. At the current soil K levels no potassium nutrient applications were required within the optimum strategy.

Table 4 Olsen P soil test levels at Year 0 and Year 10 following implementation of a VR or B fertiliser strategy on Ohorea Station The VR strategy employed is also described.

\begin{tabular}{lcccc}
\hline LMUs & Year 0 & VR strategy employed & $\begin{array}{c}\text { Year 10 } \\
\text { (VR) }\end{array}$ & $\begin{array}{c}\text { Year 10 } \\
\text { (B) }\end{array}$ \\
\hline Class 1 & 22 & $180 \mathrm{~kg} \mathrm{SSP/ha}$ & 21 & 23 \\
Class 2 - GFC & 32 & Withhold P (for 7 years* $200 \mathrm{~kg} \mathrm{SSP/ha} \mathrm{(Year} \mathrm{8} \mathrm{onwards)}$ & 17 & 26 \\
Class 2 - no crops & 18 & $170 \mathrm{~kg} \mathrm{SSP/ha}$ & 17 & 19 \\
Class 3 - Fertilised & 13 & $200 \mathrm{~kg}$ SSP/ha & 12 & 12 \\
Class 3 - Unfertilised & 8 & 100 kg Maxi SSP/ha (year 1), 140 kg SS20 /ha (year 2 on) & 8 & 4 \\
\hline
\end{tabular}

"It is assumed any greenfeed crops will be fertilised as appropriate within each year.

The VR strategy maintained soil Olsen P levels in Clas , Class 2 - no crops, Class 3 - fertilised, Class 3 Unfertilised LMUs, and decreased them on the Clas 2 - GFC LMU (Table 4). In comparison, the B strategy largely maintained soil Olsen P levels on all LMUs that we Class 3 unfertilised LMU, witholding fertiliser resulted in a reduction from Olsen P 8 to 4 by Year 10 (Table 4).

The 10 year cumulative net present value (NPV) relative to no fertiliser application of both the VR and he B strategies for Ohorea Station (Table 5) assumes hat only the effective areas, determined from visual classification of photographic imagery for the whole farm, were fertilised. The 10 year cumulative NPV's compared to no fertiliser application were greater, anging from $\$ 42$ to $\$ 410 /$ ha (average $\$ 57 /$ ha) across exception of the Class 3 - Fertilised (Table 5). For this class, the fertiliser policy was the same under either strategy. The AgResearch PKS lime econometric model optimises long-term NPV while the accumulated NPV is shown at 10 years. The negative NPV values from Class 1 and Class 2-GFC (Table 5) are a reflection of the costs of the fertiliser strategies, while the returns from increased pasture production, quality and better animal productivity from these strategies manifest over longer timeframe.

Table 5 Ten year cumulative NPV (\$/ha) relative to no fertiliser application
for Ohorea Station.

\begin{tabular}{lcc}
\hline LMUs & VR & B \\
\hline Class 1 & -277 & -319 \\
Class 2 - GFC & -143 & -553 \\
Class 2 - no crops & 204 & 149 \\
Class 3 - Fertilised & 176 & 176 \\
Class 3 - Unfertilised & 217 & 0 \\
\hline Total & 155 & 98
\end{tabular}




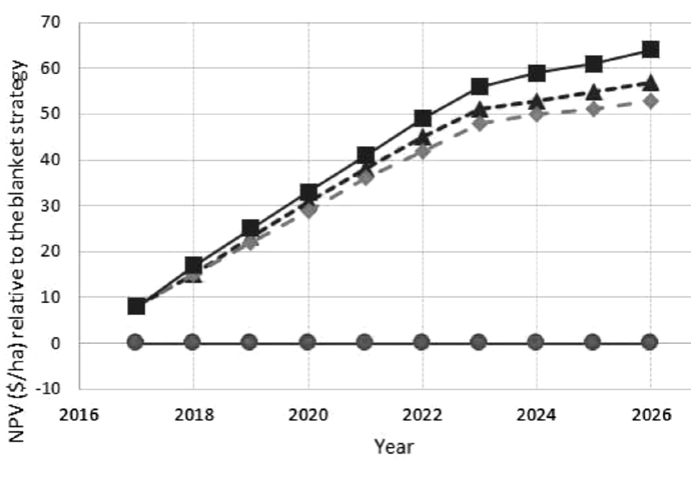

$\rightarrow$ Blanket $\quad-\rightarrow$-Modelled $\mathrm{GM} \quad-\quad \mathrm{GM}-20 \% \rightarrow-G \mathrm{M}+20 \%$

$\begin{array}{ll}\text { Figure } 1 & \text { Ten year cumulative NPV's (\$/ha) of the VR } \\ \text { strategy relative to the blanket strategy at three }\end{array}$ different GM's.

The sensitivity of the two strategies to changes in stock gross margin (GM) was tested by adjusting the GM by $\pm 20 \%$. Ten year cumulative NPV's across the farm for the VR strategy relative to the B strategy were $\$ 53$ to $\$ 64 /$ ha greater across the range of GM's tested (Figure 1). The VR strategy showed a positive NPV compared to the B strategy immediately from when the strategies were implemented at Year 1 (Figure 1).

Using hyperspectral imagery to estimate effective area in pasture

Vegetation classification from visual classification of pasture areas on the 927 ha block on Ohorea using photographic imagery, estimated $94 \%$ of the pasture area should be fertilised compared to $88 \%$ using the hyperspectral imagery (Table 6). The visual estimate excluded $61 \%$ of the non-pasture area from fertiliser application compared to $81 \%$ using the hyperspectral imagery (Table 6). These differences were due to shape effects regarding what was deemed suitable or practical for aerial application. Additionally, the automated classification excluded a higher proportion of poplar plantings in the non-pasture area.

The differences in classification of pasture and nonpasture areas has noticeable effects on the area of a hill country property that should receive fertiliser and hence the cost of fertiliser applied.

\section{Discussion}

Economic analysis of variable rate strategy

The analysis presented in this paper shows the potential benefit of the VR strategy for Ohorea Station in that it produced a higher 10 year cumulative NPV. Similarly, White et al. (2017) showed a VR strategy provided a higher NPV across modelled North and South Island higher NPV across modelled North and South Island
hill country farms across two different Olsen P fertility hill country farms across two different Olsen P fertility
levels. These results also align with the findings of a modelled study of Limestone Downs by Murray \& Yule (2007) where they concluded that a VR strategy with fertiliser applied so that it was a non-limiting factor to pasture production, excluding non-responsive areas, increased the cash surplus generated by $26 \%$ compared to a blanket application.

The gross margin sensitivity analysis on Ohorea supports previous findings (White et al. 2017) that the VR strategy, in comparison to a blanket approach, was more sustainable in terms of farm profitability in the face of volatile returns.

An important caveat to the NPV analysis shown here in respect to the value of increased fertiliser inputs, is that the FANZ vectic of farm is in a position to uilise the extra feed gown. It is assum a that exta stock ax the extra feed gown. If fextron farm labour is required to capture the extra growth from increased fertiliser inputs then that cost is not considered in this analysis. However, the econometric model does not include any management gains from changes in seasonality, or improved pasture quality and composition from increased fertiliser inputs. In general, the application of SSP fertiliser has been reported to result in a change in the botanical composition to clover and ryegrass pastures (Roberts \& White 2016), so the model analysis may alternatively be considered to be

Fertilised area classification from visual classification compared to vegetation classification from hyperspectral imagery for 927 ha of Ohorea Station.

\begin{tabular}{lccccc}
\hline Vegetation classification & $\begin{array}{c}\text { Excluded } \\
\text { (ha) }\end{array}$ & $\begin{array}{c}\text { Fertilised } \\
(\mathbf{h a})\end{array}$ & $\begin{array}{c}\text { Total } \\
\text { (ha) }\end{array}$ & $\begin{array}{c}\text { Excluded } \\
\%\end{array}$ & $\begin{array}{c}\text { Fertilised } \\
\%\end{array}$ \\
\hline Visual classification & & & & & \\
Pasture & 41.9 & 615.8 & 657.7 & 6 & 94 \\
Non Pasture & 165.2 & 104.3 & 269.5 & 61 & 39 \\
\hline Automated classification (derived from hyperspectral imagery) & & & & \\
Pasture & 76.0 & 581.7 & 657.7 & 12 & 88 \\
Non Pasture & 218.5 & 51 & 269.5 & 81 & 19 \\
\hline
\end{tabular}

conservative if farm infrastructure is appropriate or if the additional grass grown is reflected in increased slaughter weights or lambing/calving percentages from existing stock rather than purchasing additional stock.

Using hyperspectral imagery to estimate effective area in pasture

Operationally, technological advancements with the use of differential correction to GPS guidance systems combined with essing aircraft allows VR fertiliser strategies to be applied with confidence to hill country farms (Roberts \& White 2016; Morton et al. 2016). To date, Ravensdown has completed over 40 fertiliser applications on a commercial basis using this technology and from these applications, sensitive or non-productive zones have on average comprised $9 \%$ of the total land area (assessed by visual classification) of the farms indicating potential savings from more accurately quetifying the nonproductive or environmentally sensitive areas. This benefit will be enhanced if hyperspectral imagery is used to assess effective farm areas. The main difference between the methods presented here was due to shape effects regarding what was deemed suitable or practical for aerial application, and these differences would be minimised by aligning the assessment criteria. The advantage of using hyperspectral imagery is that it can overlay current digital imagery of a farm, automates what is a laborious and time consuming process and eliminates the risk of human error for assessment of effective farm area for fertiliser applications.

Early indications from the completed commercial applications using variable rate applications and exclusion zones involving SSP, are that the additional flying hours and hours to process digital maps to complete these applications suggests (according to the senior author) less the a 5\% increase in applications costs. Murray \& Yu costs. M s annual cash position when using a VR strategy only varied by $0.4 \%$

\section{ACKNOWLEDGEMENTS}

We are grateful to Atihau Whanganui Incorporated, Andrew Beijeman, Rex Martin and Siwan Shaw for their willing collaboration and involvement with Ravensdown's PGP "Pion prograve and technology.

\section{REFERENCES}

Chok, S.; Grafton M.; Yule, I.; White, M.; Manning, M. 2016. Improving aerial topdressing in New Zealan through particle ballistics modelling and accuracy trials. In: Integrated nutrient and water management for sustainable farming. Eds. Currie, L.D.; Singh, R. Occasional Report No. 29. Fertilizer and Lime Research Centre, Massey University, Palmerston North, New Zealand. 9 pp. http://flrc.massey.ac.nz/ publications.htm

Cushnahan, T.A.; Yule, I.J.; Grafton, M.C.E.; Pullanagari, R.; White, M. 2017. The classification of hill country vegetation from hyperspectral imagery. In: Science and policy: nutrient management challenges for the next generation. Eds. Currie L.D. Hedley M.J. Occasional Report No. 30. Fertilizer and Lime Research Centre, Massey University, Palmerston North, New Zealand. 10 pp. http://flrc massey.ac.nz/publications.htm

Edmeades, D.C.; McBride, R.M.; Gray, M. 2016. An assessment of current fertiliser practices in New Zealand hill country. Grassland Research and Practice Series 16: 173-178.

Lambert, M.G.; Luscombe, P.C.C Clark, D.A. 1981. Soil fertility and hill country production. Proceedings of the New Zealand Grassland Association 43: 153-160. Metherell, A.K.; Thorrold, B.S.; Woodward, S.J.R 1996. Econometric modelling for fertilise application. Proceedings of the New Zealand Grassland Association 51: 131-134.

Morton, J.D.; Roberts, A.H.C. 2009. Fertiliser use on New Zealand sheep and beef farms. 52 pp. Fertilise Association of New Zealand. http://www.fertiliser. org.nz/Site/resource center/Booklets.aspx

Morton, J.D; Stafford, A.D; Gillingham, A.G; Old, A ; Knowles, O. 2016. The development of variable rate application of fertiliser from a fixed wing topdressing aircraft. Grassland Research and Practice Series 16 : 163-167.

Murray, R.I.; Yule, I.J. 2007. Developing variable rate application technology: economic impact for farm owners and top dressing operators. New Zealand Journal of Agricultural Research 50: 53-63.

Roberts, A.H.C.; White, M.D. 2016. From there to where? Past, present and future soil fertility management on hill country farms. Grassland Research and Practice Series 16: 127-135.

Yule, I.; Gillingham, A.G. 2002. Precision agriculture for pastoral systems. Proceedings of Precision Agriculture in Australasia, A symposium on research and application. Sydney.

White, M.D.; Metherell, A.K. Roberts A.H.C. 2017. The use of variable rate fertiliser applications in NZ hill country. In: Science and policy: nutrient management challenges for the next generation. Eds. Currie, L.D.; Hedley M.J. Occasional Report No. 30. Fertilizer and Lime Research Centre, Massey University, Palmerston North, New Zealand. 13 pp. http://flrc.massey.ac.nz/publications.htm 